\title{
LOGOBOT - Um Sistema Robótico Simulador da Linguagem Logo para Auxílio no Aprendizado de Programação
}

\author{
João Paulo de A. Martins, Cassio Aquino Rocha, Bruno Amorim Ramos, Igor \\ Medeiros Vanderlei
}

\author{
Faculdade Sete de Setembro \\ Av. Vereador José Moreira, 1000 - Centro- Paulo Afonso - BA - Brasil \\ \{jpm4rtinss, cassioaquino123, bruno00amorim, igor.vanderlei\}@gmail.com
}

\begin{abstract}
This study presents a robotic system, developed to aid in the teaching/learning of fundamental concepts of computer programming activities. To achieve this goal, the system implements a subset of the teaching programming language Logo, traditionally used in teaching such concepts. In addition to the system, we designed a set of learning activities, enabling its use in the classroom. This system then was presented and approved following the methodology of evaluation by judges.
\end{abstract}

Resumo. Este trabalho apresenta um sistema robótico, desenvolvido para auxiliar nas atividades de ensino/aprendizagem dos conceitos fundamentais da programação de computadores. Para atingir este objetivo, o sistema implementa um subconjunto da linguagem de programação didática Logo, tradicionalmente utilizada no ensino de tais conceitos. Além do sistema, foi elaborado um conjunto de atividades didáticas, que possibilitem a sua utilização em sala de aula. Este sistema, em seguida, foi apresentado e aprovado seguindo a metodologia de avaliação por juizes.

\section{Introdução}

Tradicionalmente, uma parcela significativa dos alunos em séries iniciais dos cursos da área de computação apresenta problemas na aprendizagem dos conceitos fundamentais para construção de algoritmos. Isso ocorre por conta de diversos fatores, entre eles, destacam-se a dificuldade para assimilar o funcionamento sintático de uma linguagem de programação e a deficiência dos estudantes para interpretação de enunciados.

Segundo Almeida et al[2002 Apud Gomes et al 2008], a falta de sucesso está diretamente atrelada a forte carga de conceitos abstratos advindos dos conhecimentos envolvidos na atividade de programação. Ideia similar a de Pio et al[2006], que argumenta que a maior parcela da problemática ocorre pelo fato de que o aluno só terá em mãos algo realmente próximo a um produto real após a passagem por várias disciplinas, como: fundamentos da programação, algoritmo e estrutura de dados, linguagem de programação, entre outras, nas quais muito pouco, ou nada, do que é desenvolvido faz parte do que acreditam ser concreto.

Neste contexto, este trabalho apresenta um sistema baseado na união de duas ferramentas educacionais (robótica e Logo), com o objetivo de somar os benefícios de 
cada abordagem para quebrar a forte carga de abstração existente nas séries iniciais de programação.

\section{Fundamentação Teórica}

$\mathrm{Na}$ década de 60, o matemático Seymour Papert, do Instituto de tecnologia de Massachusetts (MIT), desenvolveu a linguagem Logo, uma metodologia de ensino fundamentada nos ideais: pensamento, raciocínio e discurso. O objetivo de Papert foi estimular nas crianças o raciocínio cognitivo e o pensamento sobre si mesmo, caracterizando o "entender o porquê está fazendo", conceituado pelo autor como a concretização da resolução de problemas abstratos [Pape 1985 apud Malfatti et al 2011].

A ideia por trás do ensino de programação com a linguagem Logo é simples, basicamente, o aluno recebe tarefa de desenhar uma figura geométrica através de uma tartaruga virtual, que possui uma caneta acoplada em seu casco. $\mathrm{O}$ aluno deve então elaborar uma sequência de comandos, para que a tartaruga desenhe a figura solicitada corretamente. Para realizar este tipo de atividade, o aluno não precisa ter contato com conceitos abstratos, visto que os comandos da linguagem Logo possuem relação direta com os movimentos da tartaruga: "para frente", "para trás", "girar a direita" ou "girar a esquerda", que já fazem parte do conhecimento geral.

Assim como Logo, outras ferramentas educacionais podem proporcionar ao aluno uma redução no grau de abstração de determinados conceitos. Uma dessas ferramentas é a robótica educacional.

A robótica educacional é caracterizada por ambientes de aprendizagem nos quais o aluno pode montar e programar um robô. É um instrumento que possibilita a passagem da teoria para a prática, envolvendo o conhecimento das diversas áreas e levando o aluno a agir por sua própria vontade [Castilho 2002].

Conforme Abreu et al[2011], o desenvolvimento de atividades da robótica educacional envolve, pelo menos, a concepção, construção, automação e controle do dispositivo. A realização dessas atividades em algumas escolas vem se constituindo de práticas interdisciplinares, gerando o aprendizado e uma atenção maior por parte dos alunos em sala de aula.

\section{Funcionamento do Sistema Logobot}

Logobot é um sistema composto por um conjunto de atividades pedagógicas, voltadas ao ensino dos conceitos básicos de programação, que são aplicadas através da integração de dois subsistemas: um robô, desempenhando o papel da tartaruga do Logo; e uma aplicação mobile, que funciona como controlador.

O componente robótico tem a função de receber e interpretar a mensagem advinda da interface de programação e, a partir disso, acionar o funcionamento dos motores. Quando esses comandos designam que o mecanismo deve mover os motores de forma a se deslocar de um ponto A para um ponto B, o mesmo, além de percorrer o trajeto solicitado, deve ilustrar o espaço percorrido entre esses dois pontos, com o auxílio de uma caneta presa a sua estrutura. 
O funcionamento desse artefato se dá através do uso de três motores conectados a uma placa Arduino ${ }^{1}$, dois dos motores estão conectados às rodas, e são responsáveis pelo deslocamento e o terceiro está conectado à estrutura de suporte à caneta. Além dos motores, foram utilizados os shields ${ }^{2}$ Wifly (prover conexão wi-fi) e o s4Power (controle dos motores).

Os parâmetros enviados ao robô vem da aplicação mobile, desenvolvida na plataforma Android ${ }^{3}$, que tem como objetivos: proporcionar um ambiente de construção dos algoritmos; interpretar o algoritmo fornecido pelo usuário com base na gramática Logobot; e enviar a mensagem ao componente robótico do sistema. O estágio atual do protótipo do Logobot pode ser visualizado na Figura 1, onde o elemento A representa o componente mobile e o B o componente robótico.

A

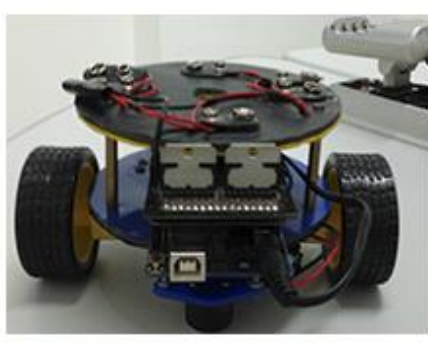

B

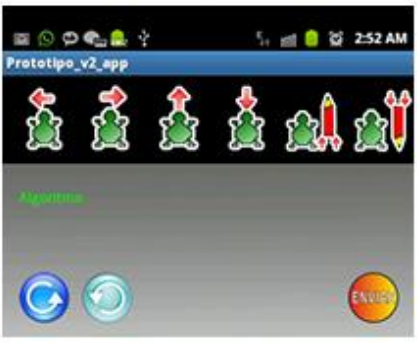

Figura 1. Protótipo atual do Logobot

O funcionamento se dá através da troca de mensagens entre os componentes, como pode ser observado na Figura 2. Quando o usuário digita um algoritmo na interface de programação, esse código é subdividido em pequenas mensagens estruturadas com base nos comandos primitivos de movimento da gramática Logobot.

Essas mensagens passam, uma a uma, por um processo de análise léxica e sintática, com o objetivo de verificar se o algoritmo está coerente com as regras de sintaxe propostas pelo interpretador de códigos do Logobot. A seguir, a mensagem é enviada ao módulo de comunicação, e, em seguida, é enviada ao artefato robótico. Com base na interpretação da mensagem, os motores devem ser acionados, provendo o deslocamento adequado. Ao final do movimento solicitado, o robô envia uma

\footnotetext{
${ }^{1}$ Arduino é uma plataforma eletrônica de código aberto cujo principal objetivo é a flexibilidade para a construção de projetos. É uma interface na qual podem ser conectados uma variedade de dispositivos como sensores, motores, etc [Arduino, s.d.].

${ }^{2}$ Os shields são placas de circuito com a finalidade de expandir a capacidade de uso do Arduino, atuando como receptores GPS, módulos de Ethernet, sensores de temperatura, etc. [Roberts 2011]

3 Android é uma plataforma móvel de código aberto, desenvolvida com base no sistema Unix, que dispõe de um kit para desenvolvimento na linguagem Java. Uma aplicação desenvolvida na plataforma Android pode recorrer a qualquer uma das funcionalidades do núcleo do telefone, como: efetuar chamadas, utilizar a camêra, enviar mensagens, etc [Darwin 2012].
} 
mensagem para o sistema mobile, indicando que já executou o movimento e está pronto para o próximo, iniciando o ciclo novamente.

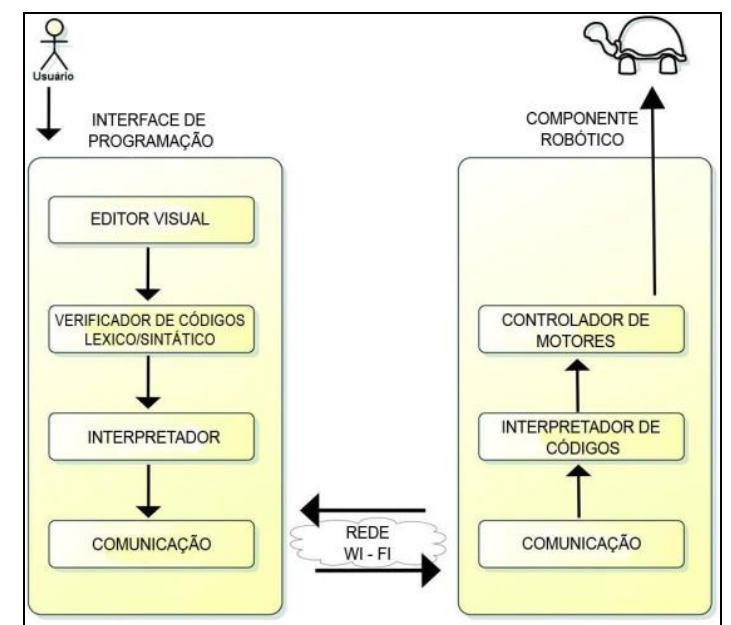

Figura 2. Caminho percorrido pela mensagem

\section{Utilização do Logobot como ferramenta de Ensino}

A aplicação do Logobot em sala de aula deve ser iniciada com a apresentação dos fundamentos básicos da linguagem Logo e dos comandos primitivos para o seu manuseio. $O$ estudante deve adquirir certo grau de intimidade com a gramática da linguagem antes de executar os exercícios, através de estímulos para exploração do seu funcionamento, com a construção e execução de programas "livres".

Concluindo a etapa de exploração, o professor pode conduzir o aprendizado dos conceitos de programação através da realização das atividades, fornecidas pelo sistema Logobot, que estão formatadas através das sequências didáticas. Cada atividade proposta foi idealizada para a construção de um conceito necessário para a aquisição da habilidade de programação de computadores, tais como "utilização de variáveis", "repetição", "controle de fluxo", entre outros. A Figura 3 apresenta uma sequência didática idealizada para o ensino do conceito de repetição com uso do Logobot.

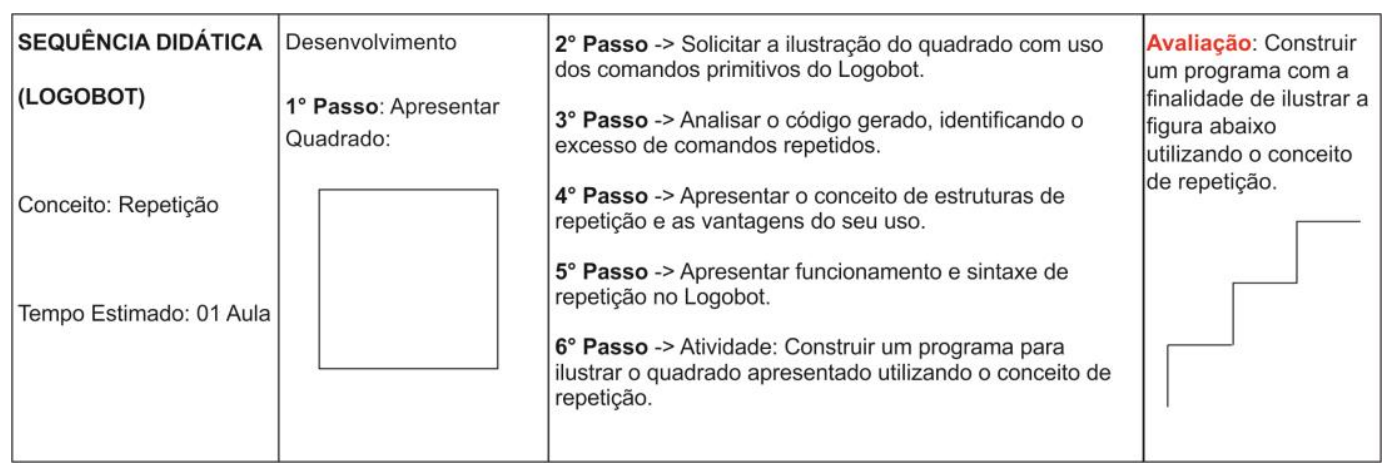

Figura 3. Sequencia didática para o ensino do conceito de repetição

\section{Conclusões e Trabalhos Futuros}

Através desse trabalho pode-se observar que a abstração existente nos fundamentos das disciplinas de programação pode ser reduzida através de tarefas interativas e práticas, 
nas quais o aluno, ao construir um programa, possa interagir com a etapa de entrada, vislumbrar a etapa de processamento, passo a passo, e usufruir de uma saída "concreta". O sistema Logobot estimula através de conceitos e exercícios, construídos com base em sequências pedagógicas, uma base teórica e prática, fundamental para o aluno nas disciplinas iniciais avançar com menos dificuldade.

Após a conclusão do protótipo inicial do Logobot, este foi submetido a uma de validação, análise utilizando o método avaliação por juízes, no qual um de grupo de cinco experientes professores de programação, do nível técnico e superior experimentou a ferramenta e considerou o sistema adequado ao ensino de programação. Ainda é preciso investigar a utilização do Logobot em sala de aula, para verificar como o sistema se comporta em um ambiente pedagógico real, aplicado ao público a que foi destinada sua construção.

Além da avaliação em sala de aula, existem outras perspectivas a trabalhos futuros envolvendo o Logobot, como o refinamento dos movimentos do componente robótico, pois a ilustração de desenhos geométricos demanda uma grande precisão. Pretende-se, também, acrescentar novas sequências didáticas, introduzindo novos exercícios e conceitos, com o intuito de reforçar a carga teórica dos fundamentos apresentados.

\section{Referências}

Abreu. J. et al (2011), "Ambiente de Robótica Pedagógica com Br GOGO e Computadores de Baixo Custo: Uma Contribuição para o Ensino Médio" http://www.br-ie.org/pub/index.php/sbie/article/view/1580, maio.

Arduino, "Arduino Software" http://www.arduino.cc, julho.

Castilho, M. I. "Robótica na Educação: Com que objetivos?" Monografia de Especialização em Informática na Educação - Universidade Federal do Rio Grande do Sul, Porto Alegre, 2002.

Darwin, (2012) "Ian F. Android CookBook". Problemas e soluções para desenvolvedores Android.

Gomes, A. et al. (2008) "Uma proposta para ajudar alunos com dificuldades na aprendizagem inicial de programação de computadores. In Educação, Formação \& Tecnoloigias; " http://eft.educom.pt/index.php/eft/article/ view/23/16, junho.

Gomes, M. C. et al 2008 "KickRobot: Inclusão Digital através da Robótica em Escolas Públicas do Rio Grande do Sul”, http://www.brie.org/pub/index.php/sbie/article/view/723/709", maio.

Malfatti, S. et al 2011 "LOGO 3D - Uma Ferramenta Auxiliar no Aprendizado da Geometria Espacial”, http://www.br-ie.org/pub/index.php/sbie/article/view/228/214, junho.

Pio, J. et al (2006) “A Robótica Móvel como Instrumento de Apoio a Aprendizagem de Computação”, br-ie.org/pub/index.php/sbie/article/viewFile/510/496, junho.

Roberts, Michae (2011) . "Arduino Básico". 